\title{
Expression and activity analysis of a new fusion protein targeting ovarian cancer cells
}

\author{
MANMAN SU ${ }^{1,2}$, WEIQIN CHANG ${ }^{1}$, DINGDING WANG ${ }^{3}$, MANHUA CUI $^{1}$, YANG LIN $^{1}$, \\ SHUYING WU ${ }^{1}$ and TIANMIN XU ${ }^{1}$
}

\author{
${ }^{1}$ Department of Obstetrics and Gynecology, The Second Hospital, and ${ }^{2}$ Department of Regenerative Medicine, \\ College of Pharmacy, Jilin University, Changchun, Jilin; ${ }^{3}$ Department of Biotechnology, College of Life Sciences \\ and Biopharmacology, Guangdong Pharmaceutical University, Guangzhou, Guangdong, P.R. China
}

Received April 22, 2015; Accepted June 15, 2015

DOI: 10.3892/or.2015.4118

\begin{abstract}
The aim of the present study was to develop a new therapeutic drug to improve the prognosis of ovarian cancer patients. Human urokinase-type plasminogen activator (uPA) ${ }_{17-34}$-kunitz-type protease inhibitor (KPI) eukaryotic expression vector was constructed and recombinant human $\mathrm{uPA}_{17-34}$-KPI (rhuPA $\left.{ }_{17-34}-\mathrm{KPI}\right)$ in $P$. pastoris was expressed. In the present study, the DNA sequences that encode uPA 17-34 amino acids were created according to the native amino acids sequence and inserted into the KPI-pPICZ $\alpha \mathrm{C}$ vector, which was constructed. Then, $\mathrm{uPA}_{17-34}-\mathrm{KPI}-\mathrm{pPICZ} \alpha \mathrm{C}$ was transformed into $P$. pastoris $\mathrm{X}-33$, and rhuPA ${ }_{17-34}-\mathrm{KPI}$ was expressed by induction of methanol. The bioactivities of a recombinant fusion protein were detected with trypsin inhibition analysis, and the inhibitory effects on the growth of ovarian cancer cells were identified using the TUNEL assay, in vitro wound-healing assay and Matrigel model analysis. The results of the DNA sequence analysis of the recombinant vector $\mathrm{uPA}_{17-34}$-KPI-pPICZ $\alpha$ demonstrated that the DNA-encoding human uPA 17-34 amino acids, 285-288 amino acids of amyloid precursor protein (APP) and 1-57 amino acids of KPI were correctly inserted into the pPICZ $\alpha \mathrm{C}$ vector. Following induction by methonal, the fusion protein with a molecular weight of $8.8 \mathrm{kDa}$ was observed using SDS-PAGE and western blot analysis. RhuPA ${ }_{17-34}$-KPI was expressed in P. pastoris
\end{abstract}

Correspondence to: Professor Tianmin $\mathrm{Xu}$, Department of Obstetrics and Gynecology, The Second Hospital, Jilin University, 218 Ziqiang Street, Changchun, Jilin 130041, P.R. China

E-mail: tianminxu@aliyun.com

Abbreviations: uPA, urokinase-type plasminogen activator; uPAR, urokinase plasminogen activator receptor; ATF, amino-terminal fragment; APP, amyloid precursor protein; KPI, kunitz-type protease inhibitor; DL-BAPNA, benzoyl-DL-arginine-p-nitroaniline; rhuPA 17 ${ }_{34}$-KPI, recombinant human $\mathrm{uPA}_{17-34}$-KPI; FBS, fetal bovine serum; CCK-8, Cell Counting Kit-8; DAB, 3,3'-diaminobenzidine; TIA, trypsin inhibition activity

Key words: urokinase-type plasminogen activator, kunitz-type protease inhibitor, ovarian cancer, $P$. pastoris, expression with a yield of $50 \mathrm{mg} / \mathrm{l}$ in a $50-\mathrm{ml}$ tube. The recombinant fusion protein was able to inhibit the activity of trypsin, inhibit growth and induce apoptosis of SKOV3 cells, and inhibit the invasion and metastasis of ovarian cancer cells. By considering $\mathrm{uPA}_{17-34}$ amino acid specific binding uPAR as the targeted part of fusion protein and utilizing the serine protease inhibitor activity of KPI, it was found that the recombinant fusion protein $\mathrm{uPA}_{17-34}-\mathrm{KPI}$ inhibited the invasion and metastasis of ovarian tumors, and may therefore be regarded as effective in targeted treatment.

\section{Introduction}

Ovarian cancer, which is a heterogeneous and rapidly progressive disease of low prevalence, is a gynecological malignant tumor with a high mortality rate (1). Due to the resistance of chemotherapy and tumor recurrence, the mortality rate among women diagnosed with metastatic diseases caused by ovarian cancer remains high, with only $27 \%$ of patients surviving $>5$ years post-diagnosis (2). Therefore, the development of new therapeutic drugs is important to improve the prognosis of ovarian cancer patients.

The human urokinase plasminogen activator (uPA) gene is located at the long arm of chromosome 10 , is $6.5 \mathrm{~kb}$ in length and consists of 11 exons, and can be transcripted into mature mRNA of $2.4 \mathrm{~kb}$ in length. The uPA is an extracellular serine protease that binds to its receptor, urokinase plasminogen activator receptor (UPAR and CD87), and converts plasminogen into plasmin at the cell-matrix interface $(3,4)$. uPA and uPAR are involved in the control of extracellular matrix turnover, cell migration, invasion and cell signaling leading to a variety of different responses under physiological and pathological conditions $(5,6)$. Previous findings indicate that during the period of cancer cell invasion and metastasis, proteolytic enzymes participate in the degradation of extracellular matrix components $(7,8)$. The specific uPA/uPAR binding results in the enzymatic activity of uPA being concentrated on the cell surface, not only reinforcing the activation of plasminogen, and consequently accelerating pathological processes such as extracellular stromatin degradation and cellular invasion, but also participating in the generation of new blood vessels closely associated with tumor metastasis $(9,10)$. uPA and 
uPAR are overexpressed in human ovarian cancer cells $(11,12)$, and the binding of UPA with UPAR on the surface of ovarian cancer cell membranes is considered as the key to promoting metastasis of ovarian cancer by uPA $(8,9)$.

uPA comprises a carboxyl-terminal serine protease domain and an amino-terminal fragment (ATF) that contains all of the determinants required for binding to its receptor. The 17-34 amino acids of ATF consist of an amino acid fragment that is crucial to uPA/uPAR binding $(13,14)$. Therefore, we aimed to create a type of fusion protein that contains uPA 17-34 amino acids and activated protein. Through targeted binding between the shortest conjugation fragment of uPA 17-34 amino acids and uPAR on ovarian cancer tissues, the fusion protein we designed was able to enter the targeted cells accurately.

The major isoforms of human amyloid precursor protein (APP), APP695 and APP751, differ due to the presence of a kunitz-type protease inhibitor (KPI) domain in the extracellular region (15). KPI is a type of stable serine protease inhibitor that inhibits the activity of serine protease and its decomposition on proteins, blocks the invasion and metastasis processes of tumor cells and recovers the cell barrier.

We constructed the pPICZ $\alpha \mathrm{C}-\mathrm{uPA}_{17-34}$-KPI expression vector which contained the nucleotide sequences encoding human uPA 17-34 and 285-345 amino acids of APP, which contained the 57 amino acid KPI domain (residues 289-345) (16). The P.pastoris expression system was then used to express the secreted recombinant human $\mathrm{uPA}_{17-34}-\mathrm{KPI}$ (rhuPA ${ }_{17-34}-\mathrm{KPI}$ ) fusion protein. By considering $\mathrm{uPA}_{17-34}$ amino acid specific binding uPAR as the targeted part of fusion protein, and utilizing serine protease inhibitor activity of KPI, the recombinant fusion protein, $\mathrm{uPA}_{17-34}-\mathrm{KPI}$, was found to inhibit the invasion and metastasis of ovarian tumors and serve as an effective targeted treatment.

\section{Materials and methods}

Strains, vectors and reagents. The DNA sequence that encodes human $\mathrm{uPA}_{17-34}$ amino acids was produced by Sangon Biotech Co., Ltd. (Shanghai, China). The P. pastoris X-33, H-DMEM culture medium and zeocin antibiotic were purchased from Invitrogen-Life Technologies (Carlsbad, CA, USA). The restrictive enzyme, T4 DNA ligase, Taq DNA polymerase and plasmid preparation kit were purchased from Takara (Biotechnology Co., Ltd., Dalian, China). SP Sepharose XL and Source ${ }^{\mathrm{TM}} 30$ RPC reversed phase hydrophobic chromatography were purchased from Phamarcia (Uppsala, Sweden). YPD, BMGY, and BMMY media were prepared as a formula (Invitrogen-Life Technologies). The SKOV3 human ovarian cancer cell line was kept in the School of Pharmaceutical Sciences of Jilin University, and KPI-pPICZ $\alpha \mathrm{C}$ was constructed in our laboratory.

Construction of the $u P A_{17-34}-K P I-p P I C Z \alpha C$ expression vector. The DNA that encodes uPA 17-34 amino acids was produced according to its native amino acids sequence (Sangon Biotech Co., Ltd). To improve the yield of recombinant protein, synonymous codons were replaced by yeast-biased codons. The DNA sequence used was: 5'-TC GAG AAG AGA GGT ACT TGT GTT TCT AAC AAG TAC TTC TCT AAC ATT CAC TGG TGT AAC TGT CCA GAG GTT GTT AGA GAG GTT TGC
A-3'; complementary strand, 5'-AAC CTC TCT AAC AAC CTC TGG ACA GTT ACA CCA GTG AAT GTT AGA GAA GTA CTT GTT AGA AAC ACA AGT ACC TCT CTT C-3'.

Annealing was performed as follows: $6 \mu 10.5 \mathrm{mmol} \mathrm{NaCl}$ and $25 \mu \mathrm{mol}$ single-strand DNA were mixed. The compound was then boiled for $3 \mathrm{~min}$ at $80^{\circ} \mathrm{C}$ and cooled down to room temperature gradually. After being annealed, the complementary strands contained cohesive ends of XhoI and PstI, while the Kex2 site was followed by the XhoI site.

KPI-pPICZ $\alpha \mathrm{C}$ was constructed and kept in our laboratory. In addition to the 57 amino acids KPI domain, the recombinant plasmid contained DNA that encodes an additional four amino acid residues that correspond to amino acids 285-288 of APP (16). The DNA sequence of 61 amino acids was inserted into pPICZ $\alpha \mathrm{C}$ between $\mathrm{XhoI}$ and $\mathrm{XbaI}$. The KPI-pPICZ $\alpha \mathrm{C}$ plasmid was digested with $X h o I$ and $P s t I$ and then the DNA sequence that encodes uPA 17-34 amino acids was inserted into the corresponding sites to construct the $\mathrm{uPA}_{17-34}-\mathrm{KPI}-$ pPICZaC expression plasmid.

The recombinant plasmid was transformed into competent cells of Escherichia coli XL-Blue, and the recombinant colonies were selected by zeocin $(25 \mu \mathrm{g} / \mathrm{ml})$ resistance. The positive clones were incubated in LB liquid medium for $12 \mathrm{~h}$ and the plasmids were extracted using a plasmid preparation kit. The nucleotide sequences of the inserted DNA and flanking sequence were verified by sequencing with the Genome Lab DTCS-Quick Start kit and CEQ 2000 DNA analysis system (Beckman Coulter Inc., Brea, CA, USA).

Transformation and induced expression of rhuPA $A_{17-34^{-}}$KPI. The recombinant plasmid with correct sequence was linearized with $S a c I$ and introduced into the competent cells of the $P$. pastoris X-33 strain by electroporation using a micropulser (Bio-Rad, Hercules, CA, USA) according to the pPICZ $\alpha$ vector manual. After electroporation, the mixture was spread on a YPD culture plate containing zeocin $(100 \mathrm{mg} / \mathrm{l})$ and cultured at $30^{\circ} \mathrm{C}$ for 3 days. The blank plasmid of pPICZ $\alpha \mathrm{C}$ was also transformed as a negative control.

After the transformants with zeocin resistance became visible, some monoclonal transformants were randomly selected and cultured in $10 \mathrm{ml} \mathrm{BMGY}$ culture medium at $30^{\circ} \mathrm{C}$ with agitation at $225 \mathrm{rpm}$ for $24 \mathrm{~h}$. The culture media $(0.5 \mathrm{ml})$ were sampled, and centrifuged at $10,000 \mathrm{rpm}$ for $5 \mathrm{~min}$ at $4^{\circ} \mathrm{C}$ and the cell pellets were used for genomic DNA analysis. The yeast genomic DNA was extracted using the boiling-freezingboiling method and PCR identification was carried out to select the $P$. pastoris $\mathrm{X}-33$ strain which was successfully. transformed into recombinant plasmid

The remaining culture medium was centrifuged and cell pellets were resuspended in $10 \mathrm{ml}$ BMMY medium to induce expression for 7 days. The culture medium $(0.5 \mathrm{ml})$ was sampled daily and centrifuged at $10,000 \mathrm{rpm}$ for $5 \mathrm{~min}$ at $4^{\circ} \mathrm{C}$. The supernatant was used for recombinant protein detection. Methanol was added every $24 \mathrm{~h}$ to a final concentration of $0.5 \%(\mathrm{v} / \mathrm{v})$ to induce the expression of the target protein. SDS-PAGE and trypsin inhibition analyses were performed to select high-level expression clone cells.

Optimized expression of rhuPA $17-34^{-}$KPI in P. pastoris. To ascertain the optimized $\mathrm{pH}$ value and induction time in 
Table I. Protocol of trypsin inhibition activity analysis of rhuPA $17-34$-KPI.

\begin{tabular}{|c|c|c|c|}
\hline Materials & $\begin{array}{l}\text { Tube } 0 \\
(\mu 1)\end{array}$ & $\begin{array}{l}\text { Tube } 1 \\
(\mu 1)\end{array}$ & $\begin{array}{l}\text { Sample tube } \\
(\mu 1)\end{array}$ \\
\hline $\begin{array}{l}\text { Tris-HCl buffer } \\
(\mathrm{pH} 8.0)\end{array}$ & 650 & 650 & 650 \\
\hline $\begin{array}{l}\text { Trypsin solution } \\
(20 \mathrm{U} / \mathrm{ml})\end{array}$ & 25 & 25 & 25 \\
\hline $\begin{array}{l}\mathrm{RhuPA}_{17-34} \text {-KPI } \\
\text { culture supernatant }\end{array}$ & 60 & 60 & 60 \\
\hline $30 \% \mathrm{HAc}$ & $\begin{array}{c}450 \\
37^{\circ} \mathrm{C} 20 \mathrm{~min}\end{array}$ & 0 & 0 \\
\hline $\begin{array}{l}\text { DL-BAPNA } \\
(200 \mathrm{mmol} / \mathrm{l})\end{array}$ & $\begin{array}{c}10 \\
37^{\circ} \mathrm{C} 10 \mathrm{~min}\end{array}$ & 10 & 10 \\
\hline $30 \%$ HAc & 0 & 450 & 450 \\
\hline
\end{tabular}

KPI, kunitz-type protease inhibitor.

order to achieve a high-level expression of rhuPA ${ }_{17-34}-\mathrm{KPI}$, a high-level expression cell colony was cultured with different $\mathrm{pH}$ values (3.5-7.5 with 0.5 intervals) using culture medium. The procedure followed was the same as mentioned above, and the $\mathrm{pH}$ values were adjusted daily with disodium hydrogen phosphate and citric acid. At the desired time points, $0.5 \mathrm{ml}$ cell aliquots were removed and replaced with equal amounts of fresh medium. The supernatant samples were used for trypsin inhibition analysis. To optimize the induction time, the supernatant samples from 0 to 7 days under the same $\mathrm{pH}$ value were detected by trypsin inhibition analysis.

SDS-PAGE and western blot analyses of rhuPA ${ }_{17-34^{-}} \mathrm{KPI}$. SDS-PAGE analysis was performed using $18 \%$ separation gel. For western blot analysis, proteins in the gel were transferred to a nitrocellulose membrane. The membrane was blocked with 5\% BSA for $1 \mathrm{~h}$ and then incubated with the murine anti-human urokinase monoclonal antibody (American Diagnostica Inc., Stamford, CA, USA) for $12 \mathrm{~h}$. After being washed, the membrane was incubated with the goat antimouse HRP-conjugated IgG (Dingguo, China), diluted to 1:250. The bound antibody was detected using 3,3'-diaminobenzidine (DAB).

Trypsin inhibition activity analysis of rhuPA ${ }_{17-34^{-}} \mathrm{KPI}$. The trypsin inhibition experiment was used to determine the activity and quantity of rhuPA ${ }_{17-34}$-KPI. As shown in Table I, $650 \mu \mathrm{l}$ Tris- $\mathrm{HCl}(50 \mathrm{mmol} / \mathrm{l}, \mathrm{pH}$ 8.0) buffer, $60 \mu 1$ culture supernatant and $25 \mu \mathrm{l}$ trypsin $(20 \mathrm{U} / \mathrm{ml})$ were mixed in $1.5-\mathrm{ml}$ tubes and incubated at $37^{\circ} \mathrm{C}$ for $20 \mathrm{~min}$. Then, $10 \mu 1 \mathrm{~N}$-benzoylDL-arginine-4-nitroanilide hydrochloride (DL-BAPNA; $200 \mathrm{mM} / \mathrm{l}$ ) was added. After being incubated at $37^{\circ} \mathrm{C}$ for $10 \mathrm{~min}$, the reaction was stopped by adding $450 \mu 130 \%$ (v/v) acetic acid. The absorbance of each tube was measured at $410 \mathrm{~nm}$. Each sample was measured three times and the mean value was used for analysis. The percentage of trypsin inhibition activity (TIA) was calculated based on the formula:

$$
\operatorname{TIA}(\%)=\frac{A 1-A s}{A 1-A o} \times 100 \%
$$

where $\mathrm{A}_{0}, \mathrm{~A}_{1}, \mathrm{~A}_{410}$ were tube 0 and 1 ; and $\mathrm{As}, \mathrm{A}_{410}$ the sample tube (tube $S$ ).

Purification of rhuPA ${ }_{17-34^{-}}$KPI. After being induced by methanol for 5 days, the supernatant of the fermentation broth was collected by centrifugation. After being diluted four times with $20 \mathrm{mM} \mathrm{NaAc}-\mathrm{HAc}(\mathrm{pH}$ 3.0) buffer, the $\mathrm{pH}$ of the supematant was adjusted to 3.0 with $1 \mathrm{M}$ acetate acid. The supernatant was loaded onto the cation exchange chromatography (SP Sepharose XL) which was equilibrated with $20 \mathrm{mM}$ NaAc-HAc (pH 3.0) buffer. The column was washed extensively with the same buffer. The bound protein was eluted with a linear gradient of $\mathrm{NaCl}(0.1-1.0 \mathrm{M})$ and protein elution was monitored by measuring the absorbance at $280 \mathrm{~nm}$ and identified by trypsin inhibition analysis. The column effluent containing rhuPA $17-34$-KPI was loaded onto a reverse phase column (Source 30) which was equilibrated with $0.1 \%$ trifluoroacetic acid (TFA) for further purification. $\mathrm{RhuPA}_{17-34}$-KPI was eluted using $50 \%$ methanol containing $0.1 \%$ TFA and was concentrated by vacuum distillation and freeze drying to remove the methanol.

$N$-terminal amino acid sequence analysis. To determine the $\mathrm{N}$-terminal sequence, the purified rhuPA ${ }_{17-34}$-KPI was electrophoresed on 18\% SDS-PAGE gel and electroblotted on a PVDF membrane. After being blotted, the PVDF membrane was stained with Coomassie Brilliant Blue R250, and the rhuPA $_{17-34}$-KPI band was extracted and determined by automated Edman degradation performed on a model PPSQ-21A protein sequencer (Shimadzu, Japan).

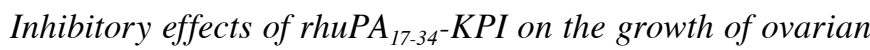
cancer cells. The growth and proliferation of SKOV3 ovarian carcinoma cells was observed using a Cell Counting Kit-8 (CCK-8) assay. Briefly, the SKOV3 human ovarian cancer cell line was maintained in H-DMEM with $10 \%$ fetal bovine serum (FBS) and $100 \mathrm{U} / \mathrm{ml}$ of penicillin/streptomycin, at $37^{\circ} \mathrm{C}$ in a humidified atmosphere containing $5 \% \mathrm{CO}_{2}$. The cells $\left(2 \times 10^{4}\right)$ were seeded in 96 -well plates containing complete medium and incubated for $24 \mathrm{~h}$ followed by different doses of rhuPA ${ }_{17-34}$-KPI. SKOV3 cells were treated with H-DMEM (as control) and 0.075, 0.15, 0.3, 0.6, 1.2 and $2.4 \mathrm{mg} / \mathrm{ml} \mathrm{rhuPA}_{17-}$ ${ }_{34}$-KPI, respectively, for $48 \mathrm{~h}$. Subsequently, $10 \mu \mathrm{l}$ of the CCK-8 solution was added to each well and the cells were incubated for $2 \mathrm{~h}$. The absorbance was detected at $450 \mathrm{~nm}$ using a microplate reader (Bio-Rad Instruments, Hercules, CA, USA). The percentage of inhibition rate of rhuPA $17-34$-KPI (I) was calculated using the formula:

$$
\mathrm{I}(\%)=\frac{A c-A s}{A c} \times 100 \%
$$

where $\mathrm{Ac}, \mathrm{A}_{450}$ was the control group; and As, $\mathrm{A}_{450}$ the different doses of rhuPA $17-34-\mathrm{KPI}$.

TUNEL assay for apoptosis. Apoptosis was determined using a TUNEL assay. SKOV 3 cells at a density of $1 \times 10^{5}$ cells/well were seeded in $1.3 \mathrm{~mm}$ coverslips in 24-well plates and incubated 
for $24 \mathrm{~h}$ followed by different doses of rhuPA ${ }_{17-34}$-KPI for $24 \mathrm{~h}$. SKOV 3 cells were treated with H-DMEM (as control), 1.2 and $2.4 \mathrm{mg} / \mathrm{ml}^{\mathrm{rhuPA}} \mathrm{P}_{17-34}-\mathrm{KPI}$, respectively, and the cells were fixed with freshly prepared paraformaldehyde [4\% in PBS ( $\mathrm{pH} 7.4)$ ], rinsed with PBS and incubated in permeabilization solution. TUNEL staining was performed with an In Situ Cell Death Detection kit (Bioss, China) according to the manufacturer's instructions. The TUNEL reaction mixture containing reaction buffer, terminal deoxynucleotidyl transferase and bromodeoxyuridine triphosphate was added onto the slides and incubated for $2 \mathrm{~h}$ at $37^{\circ} \mathrm{C}$, followed by washing and incubation with an HRP-labeled anti-bromodeoxyuridine monoclonal antibody for $30 \mathrm{~min}$ at room temperature. The presence of antigen was then visualized with diaminobenzidine. Slides were subsequently counterstained with hematoxylin and imaged under bright-field microscopy. The number of TUNEL-positive cells was counted in six different fields and representative fields were photographed. The percentages of apoptotic cells were calculated from the ratio of apoptotic cells to total cells counted.

Inhibitory effects of rhuPA $A_{17-34}-K P I$ on the cell migration of ovarian cancer cells. The effects of rhuPA ${ }_{17-34}$-KPI on the migration of SKOV3 cells were examined using the wound-healing assay (17). SKOV3 cells were cultured in 24-well plates and allowed to reach $90 \%$ confluence. The cells were wounded with a 200- $\mu 1$ pipette tip and washed with PBS. After incubation with rhuPA ${ }_{17-34}$-KPI at a concentration of 1.2 or $2.4 \mathrm{mg} / \mathrm{ml}$ for $24 \mathrm{~h}$, the migration of SKOV3 cells into the wound area was visualized and photographed.

Ovarian cancer cell invasion assay. The effects of rhuPA 17 ${ }_{34}$-KPI on the inhibition of invasion of SKOV3 cells were detected in a two-compartment Boyden chamber (Transwell) as previously described (18). Briefly, SKOV3 cells were treated with rhuPA ${ }_{17-34}-\mathrm{KPI}$ at a concentration of 1.2 or $2.4 \mathrm{mg} /$ $\mathrm{ml}$ for $24 \mathrm{~h}$. The cells were collected and resuspended with serum-free H-DMEM. Cells $\left(2 \times 10^{4}\right)$ were seeded in the upper compartment, and H-DMEM with $20 \%$ FBS was placed in the lower compartment of the Boyden chamber. After incubation at $37^{\circ} \mathrm{C}$ for $6 \mathrm{~h}$, the cells on the lower side were fixed, stained and observed. The invasion ability of tumor cells was determined by the mean value of cells migrating through the membrane.

Statistical analysis. Data are presented as means \pm SEM. Statistical analyses were performed using the Student's t-test. $\mathrm{P}<0.05$ was considered to indicate a statistically significant result.

\section{Results}

Identification of recombinant plasmid $u P A_{17-34}-K P I-p P I C Z \alpha$. Since there is a Pst I site in the DNA sequence that encodes KPI 6-8 amino acids, we created a DNA sequence that encodes uPA 17-34 amino acids and a few amino acids corresponding to the N-terminal amino acid sequence of KPI. After the uPA sequence was inserted into the KPI-pPICZ $\alpha \mathrm{C}$ plasmid (digested with $X h o \mathrm{I}$ and $P s t \mathrm{I}$ ), the recombinant plasmid uPA $_{17-34}$-KPI-pPICZ $\alpha$ was performed using DNA sequence analysis. The results of the DNA sequence analysis of the

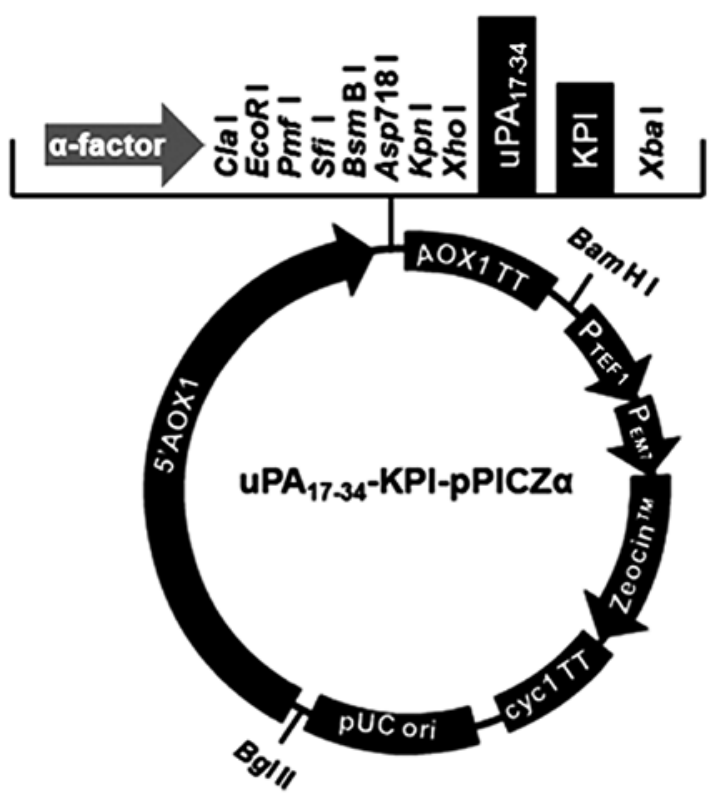

Figure 1. The schematic drawing of $\mathrm{uPA}_{17-34}$-KPI-pPICZ $\alpha$ UPA17-34-KPI which contains the DNA sequences encoding human uPA 17-34 and 285-345 amino acids of APP was inserted into the pPICZ $\alpha \mathrm{C}$ vector between the $\mathrm{XhoI}$ and $\mathrm{XbaI}$ sites. KPI, kunitz-type protease inhibitor; APP, amyloid precursor protein.

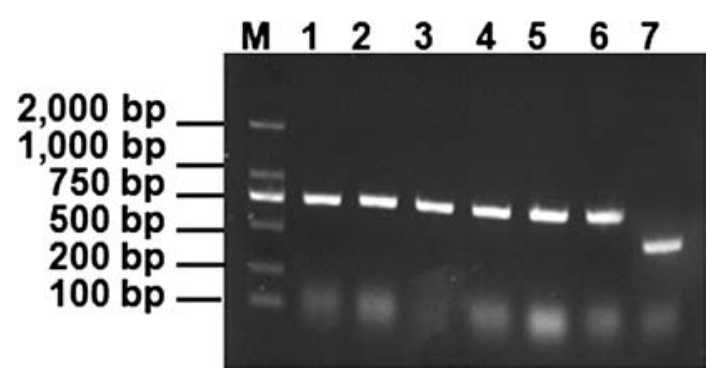

Figure 2. Agarose gel electrophoresis analysis of PCR product of the yeast genomic DNA Lane M, DL 2000 marker. Lanes 1-6, PCR products of yeast genomic DNA transformed with $\mathrm{uPA}_{17-34}-\mathrm{KPI}-\mathrm{pPICZ} \alpha$. Lane 7, PCR product of yeast genomic DNA transformed with pPICZ $\alpha \mathrm{C}$ blank plasmid. KPI, kunitz-type protease inhibitor.

recombinant expression vector $\mathrm{uPA}_{17-34}$-KPI-pPICZ $\alpha$ (data not shown) demonstrated that the DNA sequences encoding human uPA 17-34 and 285-288 amino acids of APP, and 1-57 amino acids of KPI were correctly inserted into the $\mathrm{pPICZ} \alpha \mathrm{C}$ vector and the amino acid sequence was identical to that logged in GenBank. The schematic drawing of uPA $_{17-34}$-KPI-pPICZ $\alpha$ presents the structure of recombinant plasmid (Fig. 1).

Screening of positively transformed yeast strain with PCR. After being cultured at $30^{\circ} \mathrm{C}$ for 3 days, a number of transformants with zeocin resistance became visible on the YPD agar plates containing $0.1 \mathrm{~g} / 1$ zeocin. 5'AOX and 3'AOX were used as primers to perform PCR analysis of genomic DNA. PCR products were used to carry out $1.0 \%$ agarose gel electrophoresis analysis. There were $\sim 750 \mathrm{bp}$ amplification bands for the samples that were transformed with $\mathrm{uPA}_{17-34}-\mathrm{KPI}-\mathrm{pPICZ} \alpha$, but $\sim 400$ bp for the control sample which was transformed with the pPICZ $\alpha \mathrm{C}$ blank plasmid (Fig. 2). The results showed that, the DNA sequence encoding the fusion protein was integrated 


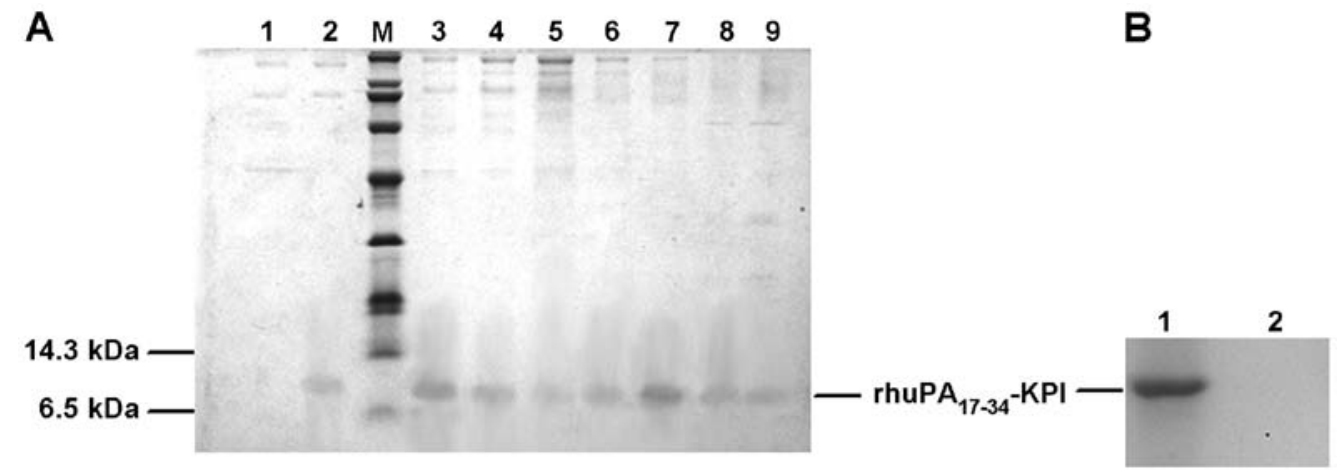

Figure 3. SDS-PAGE and western blot analyses of rhuPA $17-34$-KPI. (A) SDS-PAGE analysis of rhuPA $17-34$-KPI. SDS-PAGE was performed on $18 \%$ gel and stained with Coomassie brilliant blue. Lane M, protein molecular weight marker (broad). Lane 1, supernatant from the negative stain transformed with pPICZ $\alpha$ blank plasmid. Lanes 2-9, supernatant from different rhuPA $17-34-\mathrm{KPI}$ transformants after induction of methanol for $72 \mathrm{~h}$. (B) Western blot analysis of rhuPA $_{17-34}$-KPI. Lane 1, purified rhuPA ${ }_{17-34}$-KPI. Lane 2, supernatant from the negative stain transformed with pPICZ $\alpha \mathrm{C}$ blank plasmid as a negative control. KPI, kunitz-type protease inhibitor.

A

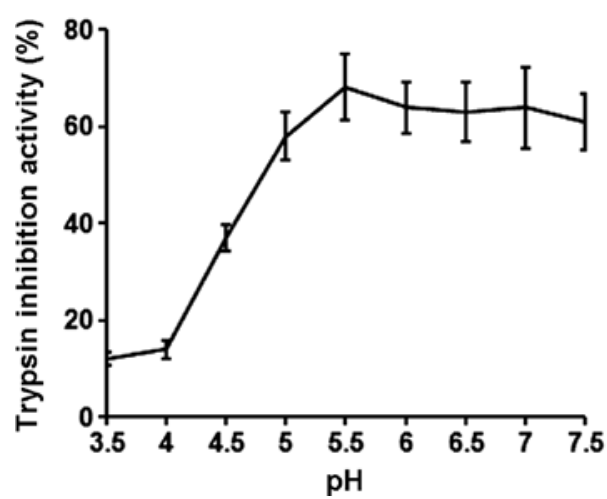

B

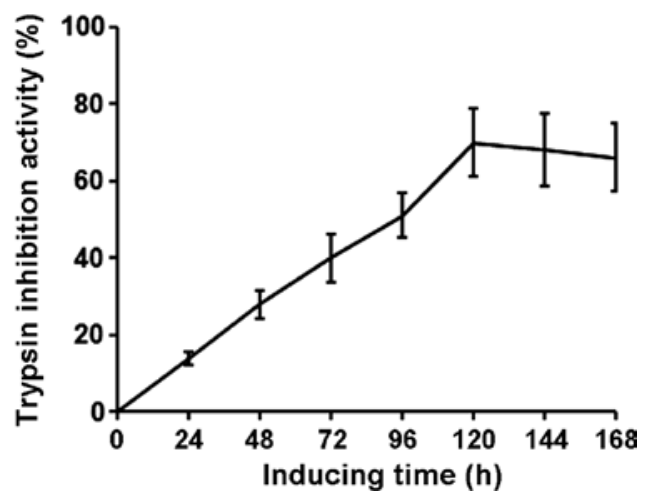

Figure 4. Optimized expression of recombinant human $\mathrm{uPA}_{17-34}$-KPI in P. pastoris. (A) Optimization of the pH value. (B) Optimization of the methanol inducing time-points. Supernatants collected at each evaluated condition were processed by trypsin inhibition activity analysis.

into $>90 \%$ of clones which were transformed with the recombinant expression vector, $\mathrm{uPA}_{17-34}-\mathrm{KPI}-\mathrm{pPICZ} \alpha$.

Expression of rhuPA $17-34-K P I$. The positive transformants were induced to express recombinant protein by methanol for 7 days. On the third day after induction with methanol the supernatants were identified using SDS-PAGE analysis and the transformant presenting with the highest expression level of rhuPA ${ }_{17-34}$-KPI was utilized to optimize the expression of the fusion protein in $P$. pastoris. The results indicated that rhuPA ${ }_{17-34}$-KPI was expressed following the induction of methanol. However, the recombinant protein expression in the transformant-containing blank plasmids of pPICZ $\alpha \mathrm{C}$ was negative. Based on the amino acids sequence, the calculated molecular weight of rhuPA ${ }_{17-34}$-KPI was $8.8 \mathrm{kDa}$, which was consistent with the result of the SDS-PAGE measurement (Fig. 3A).

Identification of rhuPA $A_{17-34}-K P I$. The primary purified recombinant protein was identified by western blot analysis. The results demonstrated that the recombinant protein bound to the anti-human urokinase monoclonal antibody. No band was observed in lane 2, which was the supernatant of transformant containing blank plasmids of pPICZ $\alpha \mathrm{C}$ (Fig. 3B).
$\mathrm{N}$-terminal amino acid sequence analysis of the purified recombinant protein offered the first 15 amino acids as G T C V S N K Y F S N I H W C. The N-terminal sequence of rhuPA ${ }_{17-34}$-KPI was identical to that of human $\mathrm{PPA}_{17-34}$, confirming the successful expression and purification of rhuPA $_{17-34}$-KPI.

Optimized expression of rhuPA $A_{17-34}-K P I$. Trypsin inhibition activity analysis was performed to determine the optimal expression conditions of rhuPA ${ }_{17-34}$-KPI. After a series of experiments, the optimal expression conditions of rhuPA 17 34-KPI were obtained as follows: the optimal $\mathrm{pH}$ was 5.5 (Fig. 4A), and the optimal induction time-points were identified on the 5th day for the strain (Fig. 4B) at $30^{\circ} \mathrm{C}$, following daily methanol addition at a concentration of $0.5 \%(\mathrm{v} / \mathrm{v})$. Under these conditions, the yield of rhuPA $_{17-34}$ KPI was $50 \mathrm{mg} / \mathrm{l}$.

Anticancer effects of rhuPA $17-34^{-K P I}$. The anticancer activity of rhuPA $17-34$-KPI was detected by its antiproliferation effects on SKOV3 cells. We observed the cell morphology of SKOV3 cells following treatment with rhuPA ${ }_{17-34}$-KPI at different doses. In the control group, the cells grew well with adherence and the cells were fusiform or diamond shaped. However, following treatment with rhuPA $17-34$-KPI, the cells 

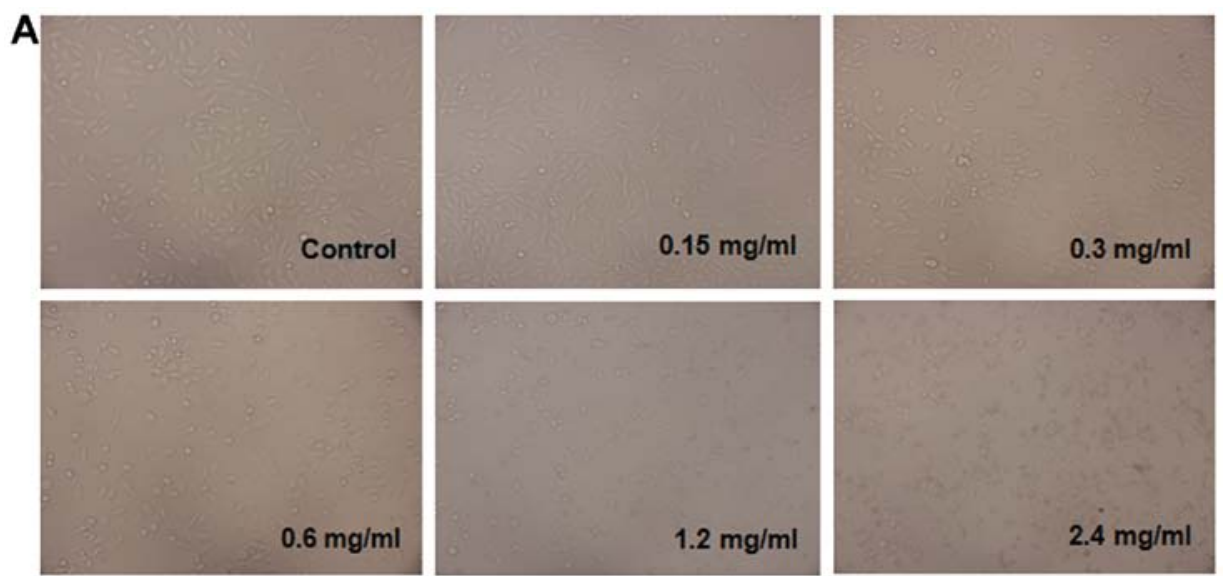

B

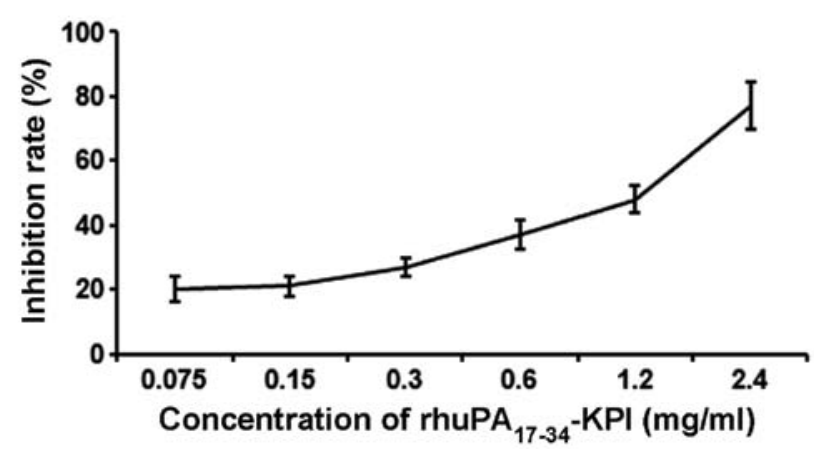

Figure 5. Inhibition effects of rhuPA $17-34-\mathrm{KPI}$ on the growth of ovarian cancer cells. (A) Morphology of rhuPA $\mathrm{A}_{17-34}$-KPI on the growth of ovarian cancer cells. (B) Dose-effect curve of rhuPA ${ }_{17-34}$-KPI on ovarian cancer SKOV3 cells. The cells were treated with H-DMEM (as control), 0.075, 0.15, 0.3, 0.6, 1.2 and $2.4 \mathrm{mg} / \mathrm{ml} \mathrm{rhuPA} \mathrm{17}_{-34}-\mathrm{KPI}$, respectively. KPI, kunitz-type protease inhibitor.
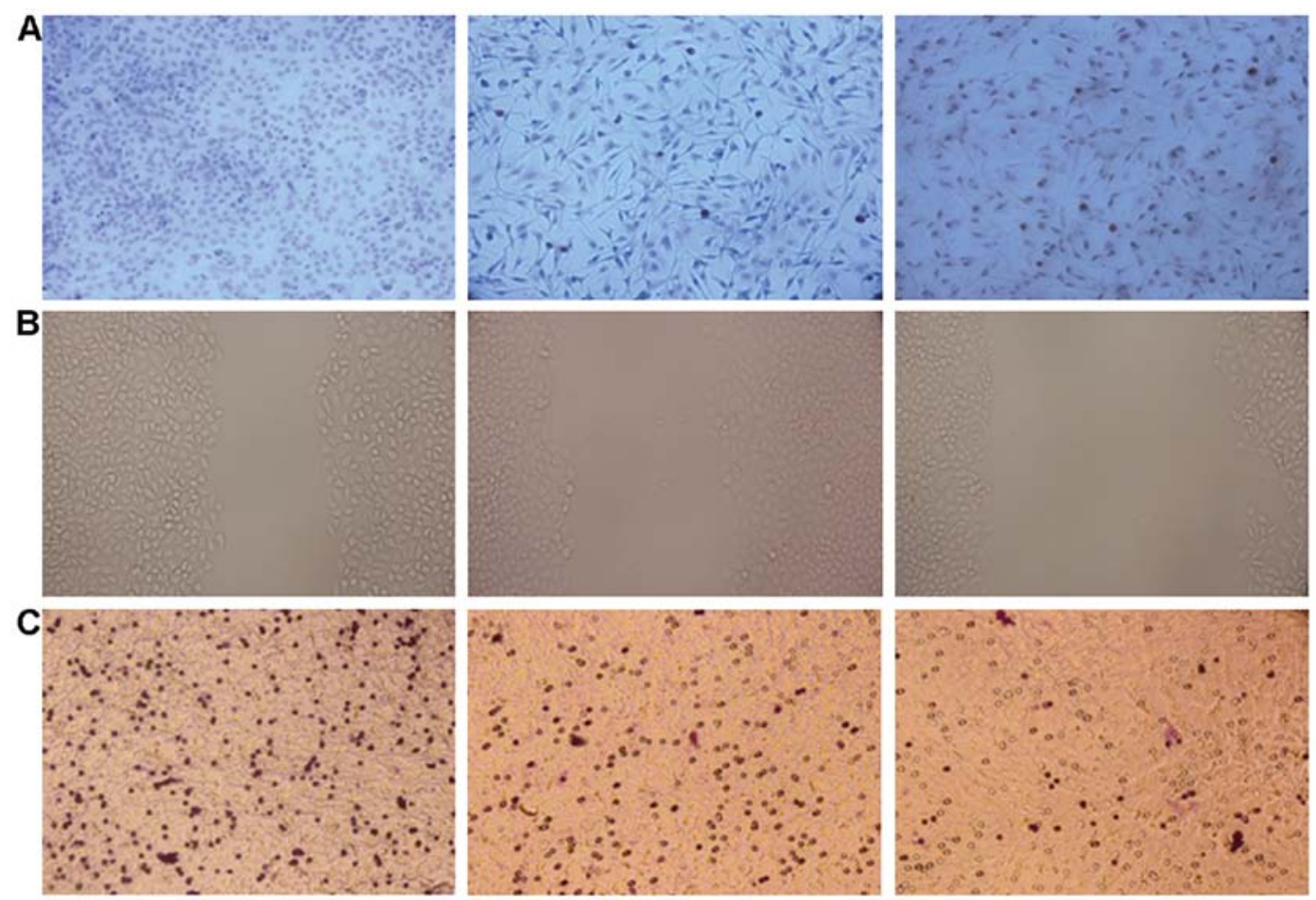

Control group

\section{$1.2 \mathrm{mg} / \mathrm{ml}^{\text {rhuPA }}{ }_{17-34}-\mathrm{KPI}$ group $2.4 \mathrm{mg} / \mathrm{ml} \mathrm{rhuPA}_{17-34}-\mathrm{KPI}$ group}

Figure 6. Anticancer effects of rhuPA $17-34$-KPI on ovarian cancer cells. (A) Morphology of TUNEL assay for apoptosis. (B) Morphology of wound-healing assay. (C) Morphology of Matrigel invasion assay. TUNEL, wound-healing and Matrigel invasion assays were detected after SKOV3 cells were treated with different concentration of rhuPA $17-34$-KPI for $24 \mathrm{~h}$. SKOVS cells were treated with H-DMEM (as control), $1.2 \mathrm{and} 2.4 \mathrm{mg} / \mathrm{ml}$ rhuPA $17-34-\mathrm{KPI}$, respectively. KPI, kunitz-type protease inhibitor. 
membrane shrinking and cytoplasm spilling were evident. The CCK-8 assay was used to detect the quantity of cells. As a result, rhuPA ${ }_{17-34}$-KPI treatment resulted in a dose-dependent inhibition of growth on SKOV3 cells at $48 \mathrm{~h}$. The inhibition rate was $\sim 80 \%$ at the dose of $2.4 \mathrm{mg} / \mathrm{ml}$ (Fig. 5).

The TUNEL assay demonstrated that ovarian cancer cells underwent apoptosis following treatment with rhuPA ${ }_{17-34}$-KPI. Data from all the designated fields were pooled to obtain the apoptosis index, which is the percentage of TUNELpositive cells in total cells manually counted in six random fields. The apoptotic indices of rhuPA $_{17-34}$-KPI treatment groups were markedly increased compared with the normal control group. As a result, rhuPA ${ }_{17-34}$-KPI treatment caused a dose-dependent increase apoptosis in SKOV3 cells within 24 h (Fig. 6A).

Inhibition of invasion and metastatic effects of rhuPA $A_{17-34}-K P I$. An in vitro wound-healing assay was performed to examine whether rhuPA ${ }_{17-34}$-KPI inhibited the migration of ovarian cancer cells. As shown in Fig. 6B, the cells in the control group that were not treated with rhuPA $_{17-34}$-KPI had migrated into and largely covered the original wound area at $24 \mathrm{~h}$ after the scratch. However, the cells treated with rhuPA ${ }_{17-34}$-KPI at different doses failed to migrate substantially into the wound area.

The effects of rhuPA ${ }_{17-34}$-KPI on the invasion of ovarian cancer cells were evaluated using the Matrigel model. $\mathrm{RhuPA}_{17-34}$-KPI reduced the number of invaded cells in a dose-dependent manner (Fig. 6C). These findings indicated that rhuPA 17-34 KPI significantly inhibited the invasion and metastasis of SKOV3 cells.

\section{Discussion}

Effective anticancer drugs are developed by clinical doctors and investigators with great effort. Surgery, chemotherapy and radiotherapy are conventional treatments used in the clinic. However, for patients considered unsuitable for surgical treatment and who do not tolerate the side effects of chemotherapy and radiotherapy, new therapeutic drugs and measures are of utmost importance. With the rapid development of molecular biology, immunology and genetic engineering technology in recent years, the focus has been on new types of drugs that have potential anticancer effects. The sequence of 17-34 amino acids of UPA is the key to UPA/uPAR binding, which makes the enzymatic activity of uPA concentrated on the cell surface $(9,10)$. Therefore, in the present study, by considering uPA 17-34 amino acids specifically binding to uPAR that is overexpressed in human ovarian cancer tissues, we determined whether the fusion protein was able to bind to target cells accurately.

Previous findings have shown that the role of the proteolytic enzyme is indispensable in the invasion and metastasis of tumor cells, and the concentrations of many serine proteases are positively correlated with tumor invasion. KPI, which was selected to utilize anticancer effects, is a type of stable serine protease inhibitor. It inhibits the activity of serine protease and its decomposition on proteins. Therefore, it is possible to block the invasive and metastastic processes of tumor cells and recover the cell barrier (19).
The present study aimed to construct the fusion protein that can be applied to effective targeted treatment for ovarian cancer. In the present study, $\mathrm{uPA}_{17-34}$-KPI-pPICZ $\alpha \mathrm{C}$ eukaryotic expression vector was constructed successfully. After being transformed into $P$. pastoris and induced by methanol, rhuPA $_{17-34}$-KPI was detected using SDS-PAGE and western blot analyses. We established a stable and effective rhuPA17KPI expression system in $P$. pastoris. The $\alpha$-factor signal peptide in the yeast expression vector was effective in guiding the secretion of rhuPA $17-34$-KPI into the culture broth, which facilitates the production of large-scale fermentation for direct industrial application without complicated purification procedures (20).

Trypsin inhibition analysis showed that huPA $_{17-34}-\mathrm{KPI}$ presented trypsin inhibition activity similar to the serine protease inhibitor. Moreover, rhuPA ${ }_{17-34}$-KPI inhibited the proliferation of SKOV3 cells and induced apoptosis of ovarian cancer cells. In vitro wound healing assay and Matrigel model analysis revealed the inhibitory effects of rhuPA ${ }_{17-34}$-KPI on the invasion and metastasis of ovarian cancer cells. Thus, the present study suggests an early-stage experimental basis for the further study of the treatment of ovarian cancer using rhuPA $_{17-34}$-KPI.

\section{Acknowledgements}

The present study was supported by grants from the National Natural Science Foundation of China (nos. 81272875, 30973187, 81401221 and 81302242), the Jilin Province Science and Technology Funds (nos. 20120957, 20130102094JC, 20140520047JH, 20140204022YY and 20150204007YY), the Jilin Province Development and Reform Commission Funds (2013C026-3), the Health Department of Jilin Province Funds (2014Q023), the Basic Scientific Research of Jilin University Funds, and grants form the Young Scholars Program of Norman Bethune Health Science Center of Jilin University (2013203019).

\section{References}

1. Watanabe T, Shibata M, Nishiyama H, Soeda S, Furukawa S, Gonda K, Takenoshita S and Fujimori K: Serum levels of rapid turnover proteins are decreased and related to systemic inflammation in patients with ovarian cancer. Oncol Lett 7: 373-377, 2014.

2. Liu SP, Yang JX, Cao DY and Shen K: Identification of differentially expressed long non-coding RNAs in human ovarian cancer cells with different metastatic potentials. Cancer Biol Med 10: 138-141, 2013.

3. Wang L, Pedroja BS, Meyers EE, Garcia AL, Twining SS and Bernstein AM: Degradation of internalized $\alpha v \beta 5$ integrin is controlled by uPAR bound uPA: Effect on $\beta 1$ integrin activity and $\alpha$-SMA stress fiber assembly. PLoS One 7: e33915, 2012.

4. Ding Y, Zhang H, Zhong M, Zhou Z, Zhuang Z, Yin H, Wang X and Zhu Z: Clinical significance of the uPA system in gastric cancer with peritoneal metastasis. Eur J Med Res 18: 28, 2013.

5. Hildenbrand R, Niedergethmann M, Marx A, Belharazem D, Allgayer H, Schleger C and Ströbel P: Amplification of the urokinase-type plasminogen activator receptor (uPAR) gene in ductal pancreatic carcinomas identifies a clinically high-risk group. Am J Pathol 174: 2246-2253, 2009.

6. Duffy MJ, McGowan PM and Gallagher WM: Cancer invasion and metastasis: Changing views. J Pathol 214: 283-293, 2008.

7. Dass K, Ahmad A, Azmi AS, Sarkar SH and Sarkar FH: Evolving role of uPA/uPAR system in human cancers. Cancer Treat Rev 34: 122-136, 2008. 
8. Botkjaer KA, Deryugina EI, Dupont DM, Gårdsvoll H, Bekes EM, Thuesen CK, Chen Z, Ploug M, Quigley JP and Andreasen PA: Targeting tumor cell invasion and dissemination in vivo by an aptamer that inhibits urokinase-type plasminogen activator through a novel multifunctional mechanism. Mol Cancer Res 10: $1532-1543,2012$.

9. Hildenbrand R, Gandhari M, Stroebel P, Marx A, Allgayer H and Arens N: The urokinase-system - role of cell proliferation and apoptosis. Histol Histopathol 23: 227-236, 2008.

10. Thummarati P, Wijitburaphat S, Prasopthum A, Menakongka A, Sripa B, Tohtong R and Suthiphongchai T: High level of urokinase plasminogen activator contributes to cholangiocarcinoma invasion and metastasis. World J Gastroenterol 18: 244-250, 2012.

11. Li H, Ye X, Mahanivong C, Bian D, Chun J and Huang S: Signaling mechanisms responsible for lysophosphatidic acidinduced urokinase plasminogen activator expression in ovarian cancer cells. J Biol Chem 280: 10564-10571, 2005.

12. Ljuca D, Fatusić Z, Iljazović E and Ahmetović B: Monitoring of chemotherapy successfulness of platina/taxol chemotherapy protocol by using determination of serum urokinase plasminogen activator (uPA) and soluble urokinase plasminogen activator receptor (suPAR) in patients with ovarian carcinoma FIGO II and III stage. Bosn J Basic Med Sci 7: 111-116, 2007.

13. Kobayashi H, Gotoh J, Fujie M, Shinohara H, Moniwa N and Terao T: Inhibition of metastasis of Lewis lung carcinoma by a synthetic peptide within growth factor-like domain of urokinase in the experimental and spontaneous metastasis model. Int $\mathbf{J}$ Cancer 57: 727-733, 1994.

14. Kobayashi H, Schmitt M, Goretzki L, Chucholowski N, Calvete J, Kramer M, Günzler WA, Jänicke F and Graeff H: Cathepsin B efficiently activates the soluble and the tumor cell receptor-bound form of the proenzyme urokinase-type plasminogen activator (Pro-uPA). J Biol Chem 266: 5147-5152, 1991.
15. Ben Khalifa N, Tyteca D, Marinangeli C, Depuydt M, Collet JF, Courtoy PJ, Renauld JC, Constantinescu S, Octave JN and Kienlen-Campard P: Structural features of the KPI domain control APP dimerization, trafficking, and processing. FASEB J 26: 855-867, 2012.

16. Wagner SL, Siegel RS, Vedvick TS, Raschke WC and Van Nostrand WE: High level expression, purification, and characterization of the Kunitz-type protease inhibitor domain of protease nexin-2/amyloid beta-protein precursor. Biochem Biophys Res Commun 186: 1138-1145, 1992.

17. Zheng HX, Wu LN, Xiao H, Du Q and Liang JF: Inhibitory effects of dobutamine on human gastric adenocarcinoma. World J Gastroenterol 20: 17092-17099, 2014.

18. Li J, Lin Y, Zhuang H and Hua ZC: Expression, purification, and biological characterization of the amino-terminal fragment of urokinase in Pichia pastoris. J Microbiol Biotechnol 23: 1197-1205, 2013

19. Godfroid E and Octave JN: Glycosylation of the amyloid peptide precursor containing the Kunitz protease inhibitor domain improves the inhibition of trypsin. Biochem Biophys Res Commun 171: 1015-1021, 1990.

20. Liu FC, Chen HL, Lin W, Tung YT, Lai CW, Hsu AL and Chen CM: Application of porcine lipase secreted by pichia pastoris to improve fat digestion and growth performance of postweaning piglets. J Agric Food Chem 58: 3322-3329, 2010. 